\title{
$N$-trans-@-caffeoyl tyramine isolated from Tribulus terrestris exerts anti-inflammatory effects in lipopolysaccharide-stimulated RAW 264.7 cells
}

\author{
HAN-JIK KO ${ }^{1 *}$, EUN-KYUNG AHN ${ }^{2 *}$ and JOA SUB OH ${ }^{1}$ \\ ${ }^{1}$ College of Pharmacy, Dankook University, Cheonan, Chungnam 330-714; ${ }^{2}$ Bio Center, \\ Gyeonggi Institute of Science and Technology Promotion, Yeongtong-gu, Suwon-si, Gyeonggi-do 443-270, Republic of Korea
}

Received February 27, 2015; Accepted July 9, 2015

DOI: 10.3892/ijmm.2015.2301

\begin{abstract}
Inflammation is induced by the expression of cyclooxygenase-2 (COX-2), which is an important mediator of chronic inflammatory diseases, such as rheumatoid arthritis, asthma and inflammatory bowel disease. Tribulus terrestris (T. terrestris) is known to have a beneficial effect on inflammatory diseases. In this study, we investigated the effects of $\mathrm{N}$-trans-Q-caffeoyl tyramine (CT) isolated from T. terrestris on the production of nitric oxide (NO), and the expression of pro-inflammatory cytokines and COX-2 in lipopolysaccharide (LPS)-stimulated RAW 264.7 cells. We also aimed to elucidate the molecular mechanisms involved. We found that the ethanolic extract of T. terrestris (EETT) and $\mathrm{CT}$ inhibited the production of NO, tumor necrosis factor- $\alpha$ (TNF- $\alpha$ ), interleukin (IL)-6 and IL-10 in the LPS-stimulated RAW 264.7 cells in a dose-dependent manner. They were determined by reverse transcription-polymerase chain reaction (RT-PCR) and enzyme-linked immunosorbent assay (ELISA). In addition, CT markedly suppressed the expression of COX-2 and the production of prostaglandin $\mathrm{E}_{2}\left(\mathrm{PGE}_{2}\right)$ in response to LPS stimulation. Furthermore, CT markedly decreased p-c-Jun N-terminal kinase (p-JNK) protein expression in LPS-stimulated RAW 264.7 cells. COX-2 and p-JNK were measured by western blot analysis. Taken together, these findings indicate that $\mathrm{CT}$ isolated from $T$. terrestris is a novel and potent modulator of inflammatory responses. Thus, it may prove benefiical to further evaluate $\mathrm{CT}$ as a possible treatment for chronic inflammatory diseases.
\end{abstract}

Correspondence to: Professor Joa Sub Oh, College of Pharmacy, Dankook University, 119 Dandae-ro, Cheonan, Chungnam 330-714, Republic of Korea

E-mail: jsoh@dankook. ac.kr

${ }^{*}$ Contributed equally

Key words: $N$-trans-Q-caffeoyl tyramine, Tribulus terrestris, antiinflammatory effect, pro-inflammatory cytokines, cyclooxygenase-2

\section{Introduction}

Tribulus terrestris (T.terrestris) is a herbal remedy that has a variety of uses in folk medicine. In traditional medicine, the extract from T.terrestris has been used to treat various diseases including hypertension, coronary heart disease (1), fungal diseases and infertility in both genders $(2,3)$. It has also been described as a highly valuable drug that can help to restore decreased liver function, and it is used in the treatment of diabetes and hyperlipidemia $(4,5)$. In traditional Chinese medicine, the fruit of $T$. terrestris has been used to treat pruritus, edema, tracheitis and inflammation (6). $\mathrm{N}$-trans-@-caffeoyl tyramine (CT) is one of the compounds isolated from T.terrestris (7). A previous study reported that $\mathrm{CT}$ acts as an antioxidant and moderately inhibits acetylcholinesterase in vitro and in vivo (8). However, the anti-inflammatory effects of CT have not yet been completely elucidated.

Inflammation is a complex pathological process mediated by diverse molecules involving a variety of immune cells, such as leukocytes, macrophages and mast cells (9). Nitric oxide (NO) and prostaglandin $\mathrm{E}_{2}\left(\mathrm{PGE}_{2}\right)$ are involved in various pathophysiological processes, including inflammation, and inducible NO synthase (iNOS) and cyclooxygenase-2 (COX-2) are mainly responsible for the production of large quantities of these mediators $(10,11)$. NO produced by the constitutive isoform of NO synthase (NOS) is a key regulator of homeostasis; however, the generation of NO by iNOS plays a significant role in inflammation (12). Activated macrophages play a pivotal role in inflammatory diseases, as they excessively produce pro-inflammatory cytokines, including tumor necrosis factor- $\alpha$ (TNF- $\alpha$ ) and inflammatory mediators, such as $\mathrm{NO}$ and $\mathrm{PGE}_{2}(13,14)$. $\mathrm{PGE}_{2}$ is another important inflammatory mediator and is produced from arachidonic acid metabolites by the catalysis of COX-2 (15). $\mathrm{PGE}_{2}$ is related to the pathogenesis of acute and chronic inflammatory states (16), and specific COX-2 inhibitors decrease the symptoms of inflammation (17).

In the present study, we examined the anti-inflammatory effects of CT isolated from $T$. terrestris on lipopolysaccharide (LPS)-stimulated RAW 264.7 cells. Our findings demonstrated that CT inhibited NO production and suppressed the expression COX-2 and cytokines related to inflammation in LPS-stimulated RAW 264.7 cells. 


\section{Materials and methods}

Preparation of T. terrestris extract. The dried fruit of T.terrestris (Fructus Tribuli) was purchased from the Gyeongdong oriental Herbal Store, Seoul, Korea, in March 2012 and was formally identified by Professor Joa Sub Oh (College of Pharmacy, Dankook University, Cheonan, Korea). A voucher specimen (G46) was deposited at the Natural Products Research Laboratory, Gyeonggi Institute of Science and Technology Promotion, Suwon, Korea. The air-dried, crushed fruits of T. terrestris $(10 \mathrm{~kg})$ were pulverized and the extract was removed with $80 \%$ ethanol (EtOH; 3x18 liters) at room temperature (twice each day for 2 days).

Extraction and isolation of CT. The $80 \%$ EtOH extract was filtered and concentrated in vacuo at $40^{\circ} \mathrm{C}$ to yield $673.5 \mathrm{~g}$ of residue, and the residue was then suspended in water and partitioned with hexane (3x1.5 liters) to produce a hexane-soluble layer (40 g). The aqueous layer was partitioned with $\mathrm{CHCl}_{3}$ to provide a $\mathrm{CHCl}_{3}$-soluble residue $(8.1 \mathrm{~g})$. The $\mathrm{CHCl}_{3}$ layer was subjected to liquid chromatography [glass column $(7 \times 20 \mathrm{~cm})$ packed with silica gel (230-400 mesh)] using $\mathrm{CHCl}_{3}: \mathrm{MeOH}(100: 0,99: 1$, 98:2, 97:3, 96:4, 94:6, 92:8, 90:10, 80:20, 70:30, 60:40, 50:50; v/v) gradient mixtures as eluents. The eluent fractions G46-51-(1-13) were obtained from this initial liquid chromatographic separation. The fractions F001-F011 were subjected to an in vitro bioassay to evaluate their NO inhibitory activity. The fraction G46-51-7 exhibited promising inhibitory activity against NO production and was thus selected for further analysis. Column chromatography of the $\mathrm{CHCl}_{3}$-soluble layer $(8.1 \mathrm{~g})$ on a silica gel using $\mathrm{MeOH}$, with increasing polarity, yielded 13 fractions, G46-51-(113). Fraction G46-51-7 (2.71 g) was further applied to flash column chromatography on a sephadex LH-20 column using $\mathrm{CHCl}_{3}: \mathrm{MeOH}$ (1:1), and 21 fractions were noted: G46-52-(1-21). Of these 21 fractions, CT $(97.5 \mathrm{mg})$ was isolated from fraction $\mathrm{G} 46-52-12$, which was precipitated with $\mathrm{CHCl}_{3}$. ${ }^{1} \mathrm{H}$ - and ${ }^{13} \mathrm{C}$-NMR spectra were recorded on a Bruker Ascend $700 \mathrm{MHz}$ spectrometer (Bruker, Billerica, MA, USA) using $\mathrm{CDCl} 3$ as a solvent. Electrospray ionization (ESI) mass spectra were obtained on an LTQ Orbitrap XL (Thermo Scientific, Bremen, Germany) mass spectrometer.

$N$-trans-Q-caffeoyl tyramine $(C T)$. Amorphous powder;

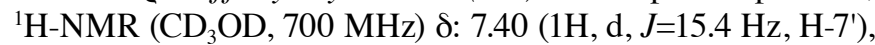
7.07 (2H, d, J=8.4 Hz, H-2, 6), 7.01 (1H, d, J=1.4 Hz, H-2'), 6.92 (1H, dd, $\left.J=8.4,2.1 \mathrm{~Hz}, \mathrm{H}-6{ }^{\prime}\right), 6.78$ (1H, d, J=8.4 Hz, H-5'), 6.74 (2H, d, J=8.4 Hz, H-3, 5), 6.35 (1H, d, J=15.4 Hz, H-8'), 3.47 $(1 \mathrm{H}, \mathrm{t}, J=7.0 \mathrm{~Hz}, \mathrm{H}-7), 2.77$ (1H, t $, J=7.0 \mathrm{~Hz}, \mathrm{H}-8) ;{ }^{13} \mathrm{C}-\mathrm{NMR}$ $\left(\mathrm{CD}_{3} \mathrm{OD}, 175 \mathrm{MHz}\right) \delta 167.9$ (C-9'), 155.5 (C-4), 147.3 (C-4'), 145.3 (C-3'), 140.8 (C-7'), 129.9 (C-1'), 129.3 (C-2, 6), 126.9 (C-1), 120.7 (C-6'), 117.0 (C-8'), 115.0 (C-5'), 114.8 (C-3, 5), 113.6 (C-2'), 41.1 (C-8), 34.4 (C-7); ESI mass spectrometry (ESIMS; negative) $m / z 298[\mathrm{M}-\mathrm{H}]^{-}$(18). The structure of CT is presented in Fig. 1A.

Reagents. The following pharmacological agents and antibodies were purchased from commercial sources: LPS from Escherichia coli serotype 0111:B4, celecoxib, $\mathrm{N}^{\mathrm{G}}$-monom ethyl-1-arginine (L-NMMA) and dexamethasone (all from Sigma-Aldrich, St. Louis, MO, USA); anti-COX-2 (M-19; sc-1747), anti- $\beta$-actin (13E5) and anti-GAPDH antibodies, and goat and mouse IgG-horseradish peroxidase conjugates (all from Santa Cruz Biotechnology, Inc., Santa Cruz, CA, USA); anti-c-Jun N-terminal protein kinase (JNK; \#9251) and anti-phospho-JNK (Thr183/Tyr185) antibodies (both from Cell Signaling Technology, Beverly, MA, USA).

Cell culture and NO assay. RAW 264.7 murine macrophages (TIB-71) were purchased from the American Type Culture Collection (ATCC, Manassas, VA, USA). The cells were maintained in Dulbecco's modified Eagle's medium (DMEM) supplemented with $10 \%$ fetal bovine serum (FBS; both from Gibco ${ }^{\circledR}$ Life Technologies, Inc., Grand Island, $\mathrm{NY}, \mathrm{USA}), 100 \mathrm{U} / \mathrm{ml}$ penicillin and $0.1 \mathrm{mg} / \mathrm{ml}$ streptomycin (both from Gibco ${ }^{\circledR}$ Life Technologies, Inc.) in a humidified atmosphere of $95 \%$ air with $5 \% \mathrm{CO}_{2}$ at $37^{\circ} \mathrm{C}$. On day 0 , the cells were seeded in 96-well plates. After $24 \mathrm{~h}$, the cells were stimulated with medium $(0.5 \mu \mathrm{g} / \mathrm{ml}$ LPS in $10 \%$ FBS-DMEM) for $2 \mathrm{~h}$, and then this medium was replaced with maintenance medium (10\% FBS-DMEM). The cells were treated with various concentrations of CT $(0-50 \mu \mathrm{M})$ for $24 \mathrm{~h}$. We then measured the levels of nitrite, a stable metabolite of NO, using Griess reagent (1\% sulfanilamide and 0.1\% N-(1-naphthyl) ethylenediamine dihydrochloride in $2.5 \%$ phosphoric acid; Sigma-Aldrich). Subsequently, the mixture was incubated at room temperature for $10 \mathrm{~min}$, and the absorbance was measured at $540 \mathrm{~nm}$. The quantity of nitrite was determined from a standard curve for sodium nitrite (Sigma-Aldrich).

Cell cytotoxicity assay. The 3-[4,5-dimethylthiazol-2-yl]2,5-diphenyltetrazolium bromide (MTT; Sigma-Aldrich) assay was used for the determination of cell viability in vitro in the RAW 264.7 cells. The cells were plated at a density of $4 \times 10^{4}$ cells/ well in $100 \mu \mathrm{l}$ culture medium. One day after plating, a time zero control plate was made. Following stimulation of the cells with LPS for $2 \mathrm{~h}, \mathrm{CT}$ was applied directly, and the cells were incubated for $24 \mathrm{~h}$ in a humidified atmosphere with $5 \% \mathrm{CO}_{2}$ at $37^{\circ} \mathrm{C}$. Cell culture was then performed. MTT $(5 \mathrm{mg} / \mathrm{ml}$ in PBS) was added to each well, followed by incubation for $90 \mathrm{~min}$. The medium was removed from the wells by aspiration; subsequently, $0.1 \mathrm{ml}$ of buffered dimethyl sulfoxide (DMSO; Sigma-Aldrich) was added to each well, and the plates were shaken. The absorbance was measured on a microtiter plate reader at $540 \mathrm{~nm}$.

Enzyme-linked immunosorbent assay (ELISA). ELISA was performed for the determination of the levels of cytokines in vitro in the RAW 264.7 cells. The cells were plated at a density of $4 \times 10^{4}$ cells/well in $100 \mu \mathrm{l}$ culture medium. One day after plating, a time zero control plate was made. Following stimulation of the cells with LPS for $2 \mathrm{~h}$, CT was applied directly and the cells were incubated for $24 \mathrm{~h}$ in a humidified atmosphere with $5 \% \mathrm{CO}_{2}$ at $37^{\circ} \mathrm{C}$. Cell culture was then performed. The supernatants were harvested and assayed for cytokines by ELISA. The concentrations of interleukin (IL)-6, IL-10 and TNF- $\alpha$ in the culture medium were quantified using a platinum ELISA kit (eBioscience, San Diego, CA, USA), and the concentration of $\mathrm{PGE}_{2}$ in the culture medium was quantified using a competitive enzyme ELISA kit (R\&D Systems, Minneapolis, MN, USA) according to the manufacturer's instructions, respectively. 
Table I. The primer sequence used for RT-PCR.

\begin{tabular}{|c|c|c|}
\hline Target & Primer sequence & Accession no. \\
\hline GAPDH & $\begin{array}{l}\text { Sense: } \quad \text { 5'-GTATGACTCCACTCACGGCAAA-3' } \\
\text { Antisense: 5'-GGTCTCGCTCCTGGAGAGATG-3' }\end{array}$ & NM_008084 \\
\hline IL-6 & $\begin{array}{ll}\text { Sense: } & \text { 5'-CACTTCACAAGTCGGAGGCTT-3' } \\
\text { Antisense: 5'-GCAAGTGCATCATCGTTGTTC-3' }\end{array}$ & NM_031168 \\
\hline IL-10 & $\begin{array}{ll}\text { Sense: } & \text { 5'-CCTGGTAGAAGTGATGCCCCAGGCA-3' } \\
\text { Antisense: 5'-CTATGCAGTTGATGAAGATGTCAAA-3' }\end{array}$ & NM_010548 \\
\hline $\mathrm{COX}-2$ & $\begin{array}{ll}\text { Sense: } & \text { 5'-GGAGAGACTATCAAGATAGTGATC-3' } \\
\text { Antisense: 5'-ATGGTCAGTAGACTTTTACAGCTC-3' }\end{array}$ & NM_011198 \\
\hline TNF- $\alpha$ & $\begin{array}{ll}\text { Sense: } & \text { 5'-AGCCTGTAGCCCACGTCGTA-3' } \\
\text { Antisense: 5'-TCTTTGAGATCCATGCCGTTG-3' }\end{array}$ & NM_013693 \\
\hline
\end{tabular}

IL, interleukin; COX-2, cyclooxygenase-2; TNF- $\alpha$, tumor necrosis factor- $\alpha$.

RNA extraction and reverse transcription-polymerase chain reaction $(R T-P C R)$. Total RNA was extracted using a total RNA extraction kit (Ambion, Carlsbad, CA, USA). Five micrograms of RNA were used as a template for each RT-PCR reaction using the SuperScript ${ }^{\text {TM }}$ III One-Step RT-PCR system (Invitrogen, Carlsbad, CA, USA). Newly synthesized cDNA from the RAW 264.7 control cells and CT-treated cells was amplified using specific primers and the Accupower ${ }^{\circledR}$ Pfu PCR PreMix (Bioneer, Daejeon, Korea). The sequences of the primers used for RT-PCR are shown in Table I.

Western blot analysis. The cells were harvested and washed with PBS and then collected by centrifugation at 13,000 rpm for $1 \mathrm{~min}$ at $4^{\circ} \mathrm{C}$. To obtain the cell lysate, the cells were lysed on ice for $30 \mathrm{~min}$ in RIPA buffer [50 mM Tris-HCl, pH 7.5, $0.15 \mathrm{M} \mathrm{NaCl}, 1 \% \mathrm{NP}-40,0.1 \%$ sodium dodecyl sulfate (SDS), $1 \mathrm{mM}$ dithiothreitol (DTT) and $1 \mathrm{mM}$ phenylmethanesulfonyl fluoride (PMSF)], which contained protease inhibitors (Roche, Mannheim, Germany). Insoluble materials were removed by centrifugation at $13,000 \mathrm{rpm}$ for $10 \mathrm{~min}$ at $4^{\circ} \mathrm{C}$. A total of $50 \mathrm{mg}$ of the supernatants was separated using a $10 \%$ polyacrylamide gel containing $10 \%$ SDS, $1.5 \mathrm{M}$ Tris- $\mathrm{HCl}, 0.035 \%$ $N, N, N^{\prime}, N^{\prime}$-tetramethylenediamine and $7 \mathrm{mg}$ ammonium persulfate. The separated proteins were electrically transferred onto a nitrocellulose membrane (Whatman, Dassel, Germany) at $36 \mathrm{~mA}$ in a transfer buffer containing $39 \mathrm{mM}$ glycine, $48 \mathrm{mM}$ Tris base, $0.037 \%$ SDS and $20 \% \mathrm{MeOH}$. All western blot analyses were performed at least in triplicate, and representative blots are shown.

Statistical analysis. Data are expressed as the means \pm SD. The statistical significance of the experimental results was analyzed (Student's t-test and one-way ANOVA with a subsequent Dunnett's multiple-range test). P-values $<0.05$ were considered to indicate statistically significant differences.

\section{Results}

Effects of CT on NO production and cytotoxicity in LPS-stimulated RAW 264.7 cells. The chemical structure of CT is illustrated in Fig. 1A. To examine the effects of CT on the inflammatory response, we measured the levels of NO production following treatment of the LPS $(0.5 \mu \mathrm{g} / \mathrm{ml})$ stimulated RAW 264.7 cells with CT $(0,5,25$ or $50 \mu \mathrm{M})$ for $24 \mathrm{~h}$. Treatment with CT induced a marked decrease in NO levels in the LPS-stimulated cells in a dose-dependent manner. Treatment with $50 \mu \mathrm{M}$ CT induced an $84.07 \%$ decrease in NO production. We also confirmed that this result was similar to that achieved by treatment with $100 \mu \mathrm{M}$ L-NMMA (Fig. 1B), as also previously demonstrated (19). To evaluate the cytotoxicity of CT, we conducted an MTT assay. Treatment with 5, 25 or $50 \mu \mathrm{M}$ CT did not have a marked cytotoxic effect on the LPS-stimulated RAW 264.7 cells (Fig. 1C).

Effects of CT on the expression and production of cytokines in LPS-stimulated RAW 264.7 cells. We investigated the effects of CT on the expression of TNF- $\alpha$, IL- 6 and IL-10, which are pro-inflammatory cytokines, in the LPS-stimulated RAW 264.7 cells. Firstly, we measured the mRNA expression levels of TNF- $\alpha$, IL- 6 and IL-10 by RT-PCR following treatment with 5, 25 or $50 \mu \mathrm{M} \mathrm{CT}$. We observed that treastment with CT suppressed the mRNA levels of TNF- $\alpha$, IL- 6 and IL-10 in a dose-dependent manner (Fig. 2A). Treatment with dexamethasone $(25 \mu \mathrm{M})$, which is a potent synthetic member of the glucocorticoid class of steroid drugs, also inhibited the mRNA expression of TNF- $\alpha$, IL-6 and IL-10 (Fig. 2A). We then confirmed the effects of CT on TNF- $\alpha$, IL- 6 and IL-10 at the protein level by ELISA. The protein levels of TNF- $\alpha$, IL- 6 and IL-10 in the conditioned medium were decreased following treatment with 5,25 or $50 \mu \mathrm{M}$ CT. In particular, treatment with $50 \mu \mathrm{M}$ CT significantly inhibited the release of TNF- $\alpha$, IL- 6 and IL-10 by up to 44.13 , 18.38 and $84.99 \%$, respectively (Fig. 2B-D).

Effects of CT on COX-2 expression and phosphorylation of mitogen-activated protein kinase (MAPK) in LPS-stimulated $R A W 264.7$ cells. To determine the effects of CT on COX-2 expression, we examined whether the expression of COX-2 is reduced at both the mRNA and protein level in LPS-stimulated RAW 264.7 cells following treatment with 5,25 or $50 \mu \mathrm{M}$ of CT. As shown in Fig. 3A, CT significantly inhibited COX-2 
<smiles>O=C(/C=C/c1ccc(O)c(O)c1)NCCc1ccc(O)cc1</smiles>
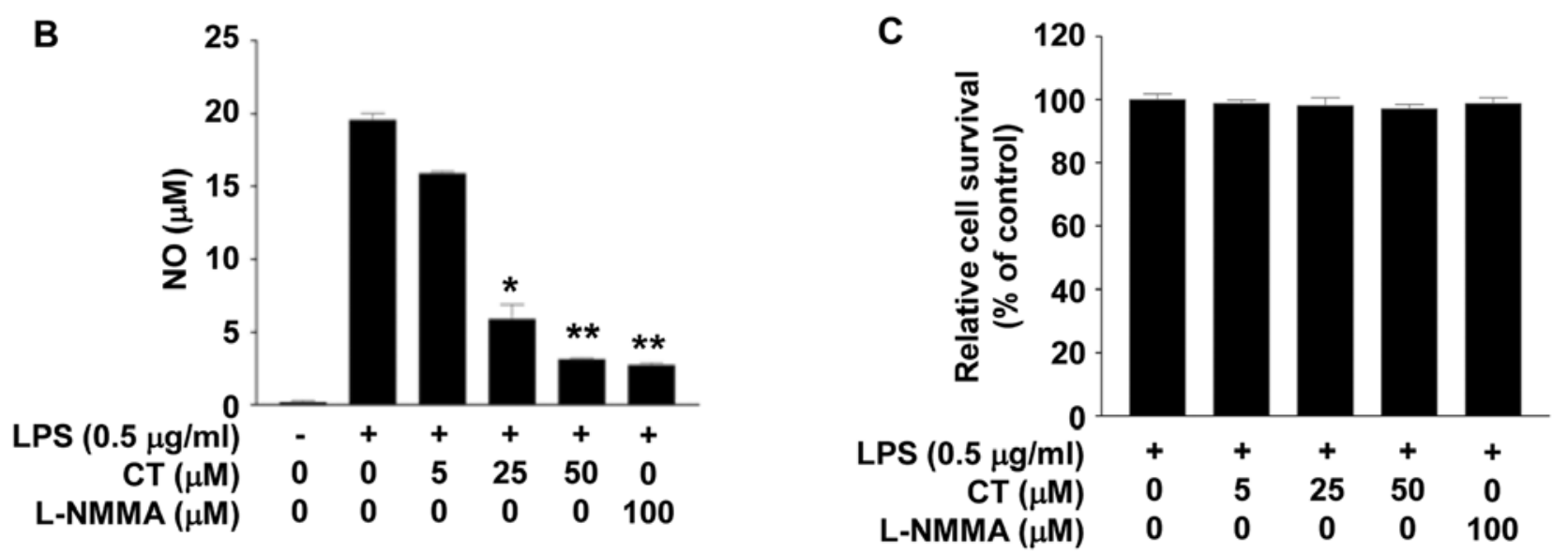

Figure 1. Effects of $\mathrm{N}$-trans-Q-caffeoyl tyramine (CT) on nitric oxide (NO) production and cytotoxicity in lipopolysaccharide (LPS)-stimulated RAW 264.7 cells (A) Structure of CT. (B) Following stimulation with LPS, the RAW 264.7 cells were treated with $0,5,25$ or $50 \mu \mathrm{M}$ of CT for $24 \mathrm{~h}$. NO assay was performed using Griess reagent. (C) Cell viability was determined by MTT assay. Results of the experiments are the mean values of 3 independent experiments and are shown as a percentage cell viability compared with the viability of the untreated cells. ${ }^{*} \mathrm{P}<0.05$ and ${ }^{* *} \mathrm{P}<0.01$, compared with the LPS-treated cells.
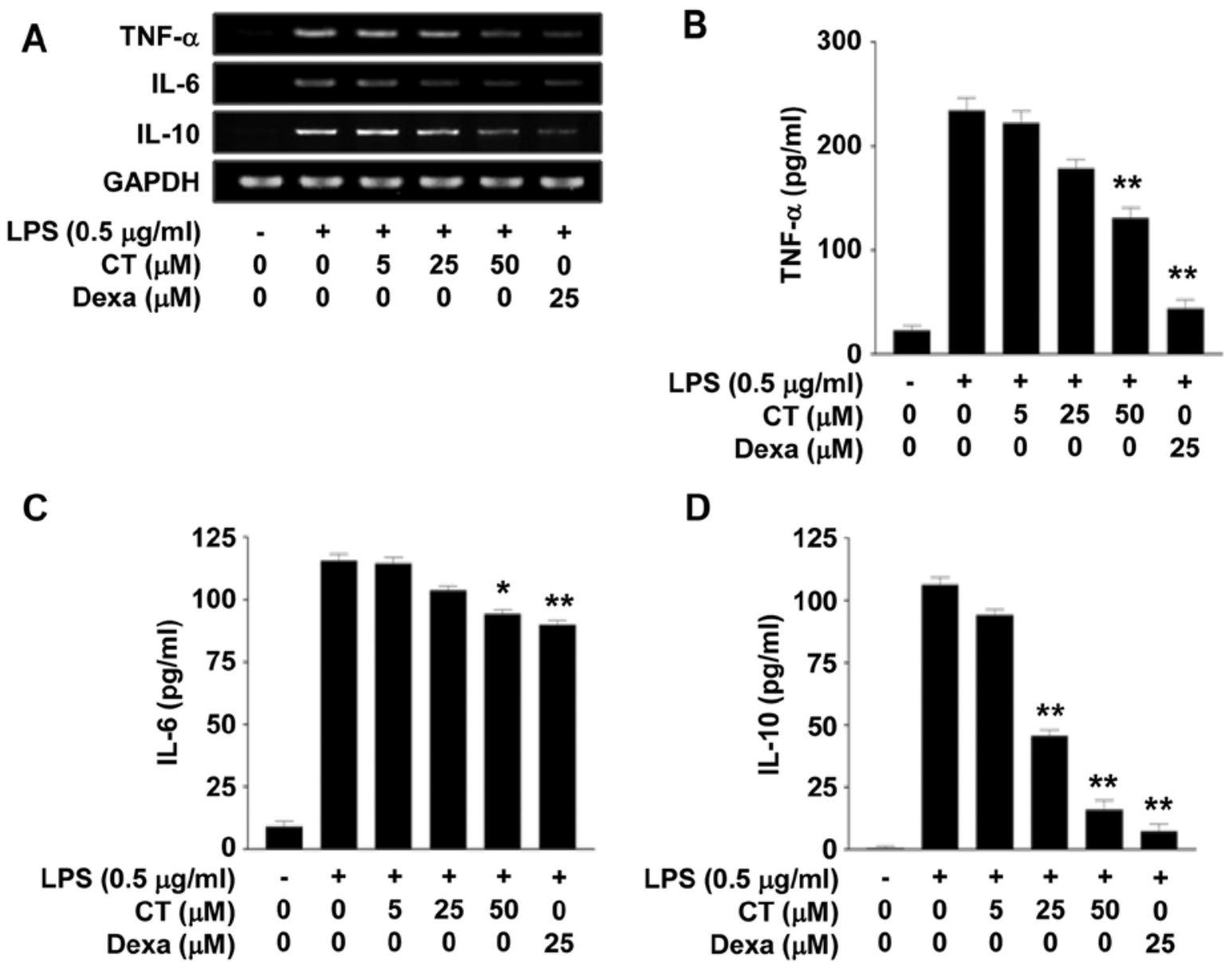

Figure 2. Effects of $N$-trans-@-caffeoyl tyramine (CT) on the expression of inflammatory cytokines in lipopolysaccharide (LPS)-stimulated RAW 264.7 cells. Following stimulation, the RAW 264.7 cells were treated with $0,5,25$ or $50 \mu \mathrm{M}$ of CT for $24 \mathrm{~h}$. (A) The representative mRNA levels of tumor necrosis factor- $\alpha$ (TNF- $\alpha$ ), interleukin (IL)-6 and IL-10 were assessed by RT-PCR. Inhibitory effects of CT on the production of (B) TNF- $\alpha$, (C) IL-6 and (D) IL-10 were assessed by enzyme-linked immunosorbent assay (ELISA). Values represent the means \pm SD of 3 independent experiments. * $\mathrm{P}<0.05$ and ${ }^{* *} \mathrm{P}<0.01$, compared with the LPS-treated cells. 

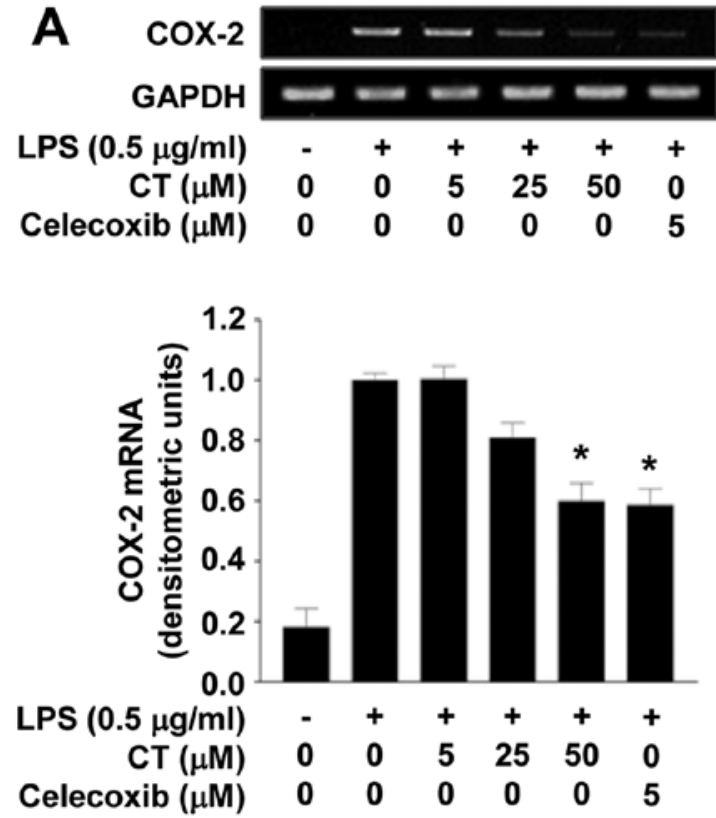
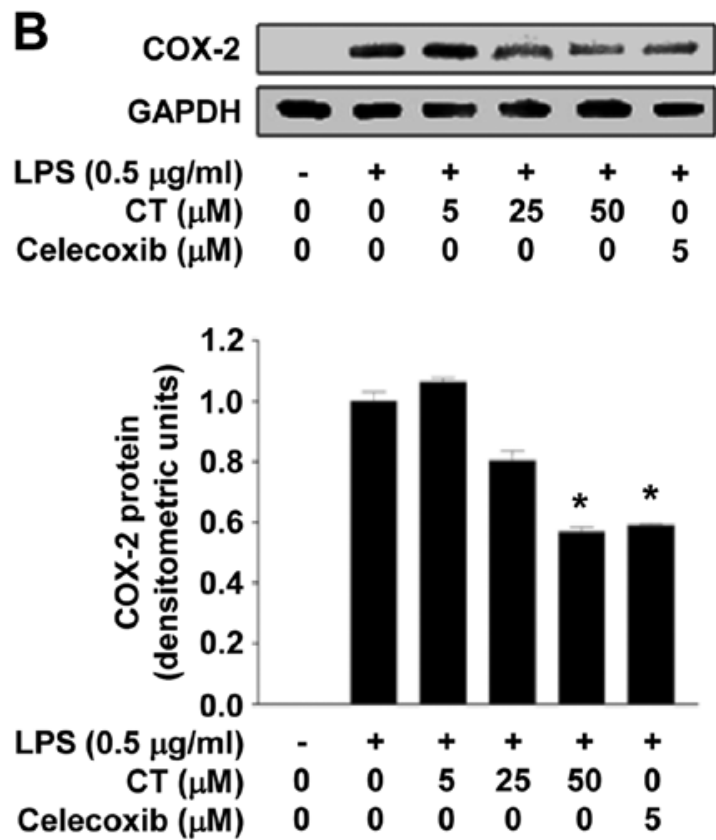

C
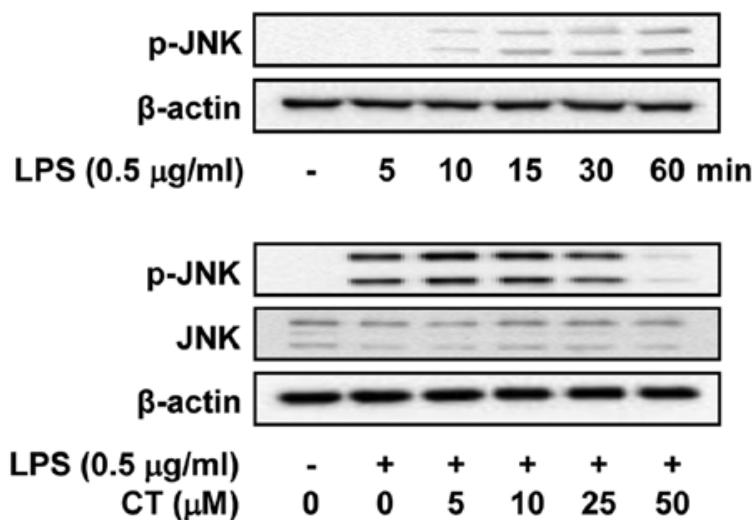

Figure 3. Effect of $N$-trans-o-caffeoyl tyramine (CT) on the expression of the cyclooxygenase-2 (COX)-2 and the phosphorylation of c-Jun N-terminal protein kinase (JNK) in lipopolysaccharide (LPS)-stimulated RAW 264.7 cells. Following stimulation, the RAW 264.7 cells were treated with $0,5,25$ or $50 \mu \mathrm{M}$ of CT for $24 \mathrm{~h}$. The CT-treated cells exhibited a decrease in (A) COX-2 mRNA expression and (B) COX-2 protein expression and (C) phosphorylation of JNK when compared with the untreated cells. We confirmed this effect by using quantitative densitometric analysis. Values represent the means \pm SD of 3 independent experiments. ${ }^{*} \mathrm{P}<0.05$, compared with the LPS-treated cells.

mRNA expression in a dose-dependent manner. Treatment with $5 \mu \mathrm{M}$ of celecoxib, a well-known COX-2 inhibitor, significantly inhibited COX-2 expression at the mRNA level. In addition, treatment with 5,25 or $50 \mu \mathrm{M}$ CT also resulted in the suppression of COX-2 expression at the protein level in a dose-dependent manner, as evidenced by western blot analysis. Treatment with celecoxib also significantly inhibited COX-2 protein expression (Fig. 3B). Studies have demonstrated that the LPS-induced phosphorylation of MAPKs leads to the production of inflammatory cytokines $(20,21)$. Thus, to determine whether the activation of the MAPK pathway is regulated by $\mathrm{CT}$, we measured the phosphorylation levels of JNK. Treatment with CT (particularly with $50 \mu \mathrm{M}$ CT) significantly inhibited the LPS-induced phosphorylation of JNK, but did not affect the expression of JNK (Fig. 3C).

Effects of CT on the PGE level in LPS-stimulated RAW 264.7 cells. To confirm the effects of CT on $\mathrm{PGE}_{2}$, one of the media- tors produced by $\mathrm{COX}-2$, we measured the secretion levels of $\mathrm{PGE}_{2}$ following treatment of the LPS-stimulated RAW 264.7 cells with CT $(5,25$ or $50 \mu \mathrm{M})$ and celecoxib $(5 \mu \mathrm{M})$. The conditioned media were collected and the $\mathrm{PGE}_{2}$ content was measured by ELISA. As shown in Fig. 4, the levels of $\mathrm{PGE}_{2}$ in the conditioned media were significantly decreased following treatment with CT $(50 \mu \mathrm{M})$ and celecoxib $(5 \mu \mathrm{M})$.

\section{Discussion}

In this study, we demonstrated that CT isolated from $T$. terrestris has a marked effect on the inflammatory response and on the levels of related pro-inflammatory cytokines in LPS-stimulated RAW 264.7 cells. We first examined the effects of an $80 \%$ ethanol extract of T.terrestris (EETT) on the inflammatory response using an NO assay, and we observed the dose-dependent suppression of NO production in the LPS-stimulated RAW 264.7 cells (data 


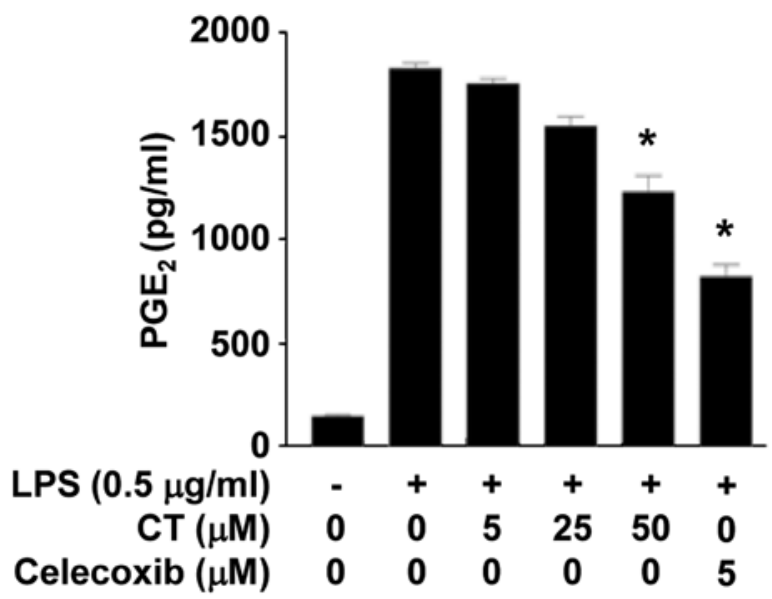

Figure 4. Effect of $N$-trans-Q-caffeoyl tyramine (CT) on the production of prostaglandin $\mathrm{E}_{2}\left(\mathrm{PGE}_{2}\right)$ in lipopolysaccharide (LPS)-stimulated RAW 264.7 cells. Following stimulation, the RAW 264.7 cells were treated with 0,5 , 25 or $50 \mu \mathrm{M} \mathrm{CT}$ for $24 \mathrm{~h}$. $\mathrm{PGE}_{2}$ secretion from the RAW 264.7 cells was determined using an enzyme-linked immunosorbent assay (ELISA). Values represent the means \pm SD of 3 independent experiments. ${ }^{*} \mathrm{P}<0.05$, compared with the LPS-treated cells.

not shown). A previous study demonstrated that $T$. terrestris inhibited COX-2 expression using the promoter assay (22). In the present study, we isolated CT from the EETT, and we examined its anti-inflammatory effects on RAW 264.7 murine macrophages. We demonstrated that treatment with $\mathrm{CT}$ resulted in a decrease in NO production in the LPS-stimulated macrophages and that it did not cause cytotoxicity under our experimental conditions. We also observed that treatment with $100 \mu \mathrm{M}$ L-NMMA, a well-known NOS inhibitor, decreased NO production in the LPS-stimulated macrophages (Fig. 1B).

Macrophages are known to play a key role in the host defense mechanism; they are activated by exposure to interferon- $\gamma$, pro-inflammatory cytokines and bacterial LPS (10). NO is endogenously generated from L-NMMA by NOS, and it plays an important role in the regulation of a number of physiological processes (23). TNF- $\alpha$, IL- 6 and IL-10 are the most important pro-inflammatory cytokines. The cytokines, TNF- $\alpha$, IL- 6 and IL-10, are produced mainly by activated monocytes or macrophages (24). In the present study, we noted that the LPS-stimulated cells exhibited increased levels of expression and production of pro-inflammatory cytokines compared to the unstimulated cells. Our data indicated that treatment with CT reduced the expression of TNF- $\alpha$, IL-6 and IL-10 at the mRNA level (Fig. 2A), and it suppressed the secretion of TNF- $\alpha$, IL- 6 and IL-10 at the protein level in the LPS-treated macrophages (Fig. 2B).

Glucocorticoids are a class of steroid hormones with pleiotropic effects. At pharmacological concentrations, glucocorticoids are used to prevent and suppress inflammation and the activation of the immune system. Steroids exert their anti-inflammatory effects mainly by modulating the transcription of a variety of genes involved in controlling inflammatory processes (25). Our results indicated that treatment with dexamethasone, which is one of the glucocorticoids, induced a decrease in the levels of TNF- $\alpha$, IL- 6 and IL-10 by up to 81.39 , 22.19 and $93.13 \%$, respectively (Fig. 2B-D). However, glucocor- ticoids are known to have serious side-effects (26), and hence it was our aim to obtain a drug from natural sources.

Prostaglandins (PGs) are key inflammatory mediators; they are produced from the conversion of arachidonic acid by COX. There are two isoforms of COX: COX-1 and COX-2 (27). COX-1 is the constitutively expressed isoform under normal physiological conditions, whereas COX-2 is expressed in response to inflammatory signals, such as cytokines and the bacteria endotoxin LPS. Celecoxib, which is a COX-2 selective inhibitor, is a useful drug for the treatment of acute pain and chronic inflammatory diseases, particularly arthritis (28); however, it is known to cause various side-effects. In this study, we demonstrated that treatment of the cells with 25 or $50 \mu \mathrm{M}$ of $\mathrm{CT}$, or $5 \mu \mathrm{M}$ celecoxib, inhibited the expression of COX-2 at the mRNA and protein level (Fig. 3A and B). These findings suggest that $\mathrm{CT}$ isolated from $T$. terrestris exerts a therapeutic effect and prevents inflammatory responses by acting as a COX-2 selective inhibitor, and may thus be a potentially safe naturally-derived drug which may be used in the treatment of inflammatory diseases. Salvemini et al reported that NO modulates the activity of COX-2 and plays a role in the release of $\mathrm{PGE}_{2}$ by activating COX-2 (29). COX-2 produces large amounts of $\mathrm{PGE}_{2}$ that induce an inflammatory response (17). Therefore, the release of the inflammatory mediator $\mathrm{PGE}_{2}$ is promoted by COX-2 activation. Our results demonstrated that treatment with $\mathrm{CT}(50 \mu \mathrm{M})$ induced a $32.70 \%$ decrease in $\mathrm{PGE}_{2}$ levels (Fig. 4). These results suggest that CT exerts an anti-inflammatory effect by suppressing COX-2 expression, which results in the inhibition of $\mathrm{PGE}_{2}$ synthesis.

In conclusion, in this study, we demonstrated that CT can markedly inhibited macrophage-mediated inflammatory responses through the suppression of the production of $\mathrm{NO}$ and pro-inflammatory cytokines, such as TNF- $\alpha$, IL-6 and IL-10. Moreover, CT inhibited the expression of COX-2, the phosphorylation of $\mathrm{JNK}$ and $\mathrm{PGE}_{2}$ synthesis. These findings suggest that CT has a therapeutic effect and may be used to prevent inflammatory diseases. Thus, it can be considered as a potential drug candidate for the treatment of arthritis and other inflammatory diseases, functioning as a COX-2-specific inhibitor.

\section{Acknowledgements}

The present study was conducted by the research fund of Dankook University in 2013.

\section{References}

1. Phillips OA, Mathew KT and Oriowo MA: Antihypertensive and vasodilator effects of methanolic and aqueous extracts of Tribulus terrestris in rats. J Ethnopharmacol 104: 351-355, 2006.

2. Adimoelja A: Phytochemicals and the breakthrough of traditional herbs in the management of sexual dysfunctions. Int $\mathrm{J}$ Androl 23 (Suppl 2): 82-84, 2000.

3. Zhang JD, Cao YB, Xu Z, Sun HH, An MM, Yan L, Chen HS Gao PH, Wang Y, Jia XM and Jiang YY: In vitro and in vivo antifungal activities of the eight steroid saponins from Tribulus terrestris $\mathrm{L}$. with potent activity against fluconazole-resistant fungal pathogens. Biol Pharm Bull 28: 2211-2215, 2005.

4. Chu S, Qu W, Pang X, Sun B and Huang X: Effect of saponin from Tribulus terrestris on hyperlipidemia. Zhong Yao Cai 26: 341-344, 2003 (In Chinese).

5. Amin A, Lotfy M, Shafiullah M and Adeghate E: The protective effect of Tribulus terrestris in diabetes. Ann NY Acad Sci 1084: 391-401, 2006. 
6. Jiangsu New Medical College: Dictionary of the Chinese Herbal Medicine. Shanghai People's Publishing House, Shanghai, p1274, 1977.

7. Lv AL, Zhang N, Sun MG, Huang YF, Sun Y, Ma HY, Hua HM and Pei YH: One new cinnamic imide dervative from the fruits of Tribulus terrestris. Nat Prod Res 22: 1013-1016, 2008.

8. Al-Taweel AM, Perveen S, El-Shafae AM, Fawzy GA, Malik A, Afza N, Iqbal L and Latif M: Bioactive phenolic amides from Celtis africana. Molecules 17: 2675-2682, 2012.

9. Willeaume V, Kruys V, Mijatovic T and Huez G: Tumor necrosis factor-alpha production induced by viruses and by lipopolysaccharides in macrophages: similarities and differences. J Inflamm 46: 1-12, 1995-1996.

10. Xie QW, Whisnant R and Nathan C: Promoter of the mouse gene encoding calcium-independent nitric oxide synthase confers inducibility by interferon $\gamma$ and bacterial lipopolysaccharide. $\mathbf{J}$ Exp Med 177: 1779-1784, 1993.

11. Vane JR, Mitchell JA, Appleton I, Tomlinson A, Bishop-Bailey D, Croxtall $\mathbf{J}$ and Willoughby DA: Inducible isoforms of cyclooxygenase and nitric-oxide synthase in inflammation. Proc Natl Acad Sci USA 91: 2046-2050, 1994.

12. Nathan C and Xie QW: Nitric oxide synthases: roles, tolls, and controls. Cell 78: 915-918, 1994

13. Yoon WJ, Ham YM, Yoo BS, Moon JY, Koh J and Hyun CG Oenothera Iaciniata inhibits lipopolysaccharide induced production of nitric oxide, prostaglandin E2, and proinflammatory cytokines in RAW264.7 macrophages. J Biosci Bioeng 107: 429-438, 2009.

14. Reddy DB and Reddanna P: Chebulagic acid (CA) attenuates LPS-induced inflammation by suppressing NF-kappaB and MAPK activation in RAW 264.7 macrophages. Biochem Biophys Res Commun 381: 112-117, 2009.

15. Murakami A and Ohigashi H: Targeting NOX, INOS and COX-2 in inflammatory cells: Chemoprevention using food phytochemicals. Int J Cancer 121: 2357-2363, 2007.

16. Hinz B, Brune K and Pahl A: Prostaglandin E(2) upregulates cyclooxygenase-2 expression in lipopolysaccharide-stimulated RAW 264.7 macrophages. Biochem Biophys Res Commun 272: 744-748, 2000

17. Crofford LJ, Lipsky PE, Brooks P, Abramson SB, Simon LS and van de Putte LB: Basic biology and clinical application of specific cyclooxygenase-2 inhibitors. Arthritis Rheum 43: 4-13, 2000

18. Chen T,He J,Zhang J, Li X,Zhang H,Hao J and Li L: The isolation and identification of two compounds with predominant radica scavenging activity in hempseed (seed of Cannabis sativa L.). Food Chem 134: 1030-1037, 2012.
19. Olken NM and Marletta MA: $\mathrm{N}^{\mathrm{G}}$-methyl-L-arginine functions as an alternate substrate and mechanism-based inhibitor of nitric oxide synthase. Biochemistry 32: 9677-9685, 1993.

20. Uto T, Suangkaew N, Morinaga O, Kariyazono H, Oiso S and Shoyama Y: Eriobotryae folium extract suppresses LPS-induced iNOS and COX-2 expression by inhibition of NF-kappaB and MAPK activation in murine macrophages. Am J Chin Med 38: 985-994, 2010.

21. Yu T, Lee YJ, Yang HM, Han S, Kim JH, Lee Y, Kim C, Han MH, Kim MY, Lee J and Cho JY: Inhibitory effect of Sanguisorba officinalis ethanol extract on $\mathrm{NO}$ and $\mathrm{PGE}_{2}$ production is mediated by suppression of NF- $\mathrm{KB}$ and AP-1 activation signaling cascade. J Ethnopharmacol 134: 11-17, 2011.

22. Hong CH, Hur SK, Oh OJ, Kim SS, Nam KA and Lee SK: Evaluation of natural products on inhibition of inducible cyclooxygenase (COX-2) and nitric oxide synthase (iNOS) in cultured mouse macrophage cells. J Ethnopharmacol 83: 153-159, 2002.

23. Dawson TM, Dawson VL and Snyder SH: A novel neuronal messenger molecule in brain: the free radical, nitric oxide. Ann Neurol 32: 297-311, 1992.

24. Dinarello CA: Proinflammatory cytokines. Chest 118: 503-508, 2000.

25. Walker G, Pfeilschifter J and Kunz D: Mechanisms of suppression of inducible nitric-oxide synthase (iNOS) expression in interferon (IFN)-gamma-stimulated RAW 264.7 cells by dexamethasone. Evidence for glucocorticoid-induced degradation of iNOS protein by calpain as a key step in post-transcriptional regulation. J Biol Chem 272: 16679-16687, 1997.

26. Boumpas DT, Chrousos GP, Wilder RL, Cupps TR and Balow JE: Glucocorticoid therapy for immune-mediated diseases: basic and clinical correlates. Ann Intern Med 119: 1198-1208, 1993.

27. Mitchell JA, Larkin S and Williams TJ: Cyclooxygenase-2: regulation and relevance in inflammation. Biochem Pharmacol 50: 1535-1542, 1995

28. Chiba A, Mizuno M, Tomi C, Tajima R, Alloza I, di Penta A, Yamamura T, Vandenbroeck K and Miyake S: A 4-trifluoromethyl analogue of celecoxib inhibits arthritis by suppressing innate immune cell activation. Arthritis Res Ther 14: R9, 2012.

29. Salvemini D, Misko TP, Masferrer JL, Seibert K, Currie MG and Needleman P: Nitric oxide activates cyclooxygenase enzymes. Proc Natl Acad Sci USA 90: 7240-7244, 1993. 